\title{
Variability of insulin sensitivity during the first 4 days of critical illness: implications for tight glycemic control
}

Christopher G Pretty ${ }^{1}$, Aaron J Le Compte ${ }^{1}$, J Geoffrey Chase ${ }^{1 *}$, Geoffrey M Shaw², Jean-Charles Preiser ${ }^{3}$, Sophie Penning ${ }^{4}$ and Thomas Desaive ${ }^{4^{*}}$

\begin{abstract}
Background: Effective tight glycemic control (TGC) can improve outcomes in critical care patients, but it is difficult to achieve consistently. Insulin sensitivity defines the metabolic balance between insulin concentration and insulin-mediated glucose disposal. Hence, variability of insulin sensitivity can cause variable glycemia. This study quantifies and compares the daily evolution of insulin sensitivity level and variability for critical care patients receiving TGC.

Methods: This is a retrospective analysis of data from the SPRINT TGC study involving patients admitted to a mixed medical-surgical ICU between August 2005 and May 2007. Only patients who commenced TGC within 12 hours of ICU admission and spent at least 24 hours on the SPRINT protocol were included $(N=164)$. Model-based insulin sensitivity $(S)$ was identified each hour. Absolute level and hour-to-hour percent changes in S/ were assessed on cohort and per-patient bases. Levels and variability of S/ were compared over time on 24-hour and 6-hour timescales for the first 4 days of ICU stay.

Results: Cohort and per-patient median S/ levels increased by 34\% and 33\% ( $p<0.001)$ between days 1 and 2 of ICU stay. Concomitantly, cohort and per-patient $S /$ variability decreased by $32 \%$ and $36 \%(p<0.001)$. For $72 \%$ of the cohort, median SI on day 2 was higher than on day 1 . The day $1-2$ results are the only clear, statistically significant trends across both analyses. Analysis of the first 24 hours using 6-hour blocks of $S /$ data showed that most of the improvement in insulin sensitivity level and variability seen between days 1 and 2 occurred during the first 12-18 hours of day 1 .

Conclusions: Critically ill patients have significantly lower and more variable insulin sensitivity on day 1 than later in their ICU stay and particularly during the first 12 hours. This rapid improvement is likely due to the decline of counter-regulatory hormones as the acute phase of critical illness progresses. Clinically, these results suggest that while using TGC protocols with patients during their first few days of ICU stay, extra care should be afforded. Increased measurement frequency, higher target glycemic bands, conservative insulin dosing, and modulation of carbohydrate nutrition should be considered to minimize safely the outcome glycemic variability and reduce the risk of hypoglycemia.
\end{abstract}

Keywords: Critical care, Hyperglycemia, Insulin resistance, Mathematical model, Algorithms

\footnotetext{
* Correspondence: geoff.chase@canterbury.ac.nz; tdesaive@ulg.ac.be

'Department of Mechanical Eng, Centre for Bio-Engineering,

University of Canterbury, Private Bag 4800, Christchurch 8054, New Zealand

${ }^{4}$ Cardiovascular Research University of Liege, Liege, Belgium

Full list of author information is available at the end of the article
} 


\section{Background}

Safe, effective tight glycemic control (TGC) of critically ill patients can improve outcomes [1-4], but it is difficult to achieve consistently [5-7]. Glycemic level and variability in TGC are a function of variability in insulin sensitivity, potentially resulting from the level and evolution of the stress response [8], and are independently associated with mortality [9-12].

Insulin sensitivity defines the metabolic balance between insulin concentration and glucose disposal. Insulin-mediated glucose disposal is a dominant pathway to reduce and control glycemia in critically ill patients. For a fixed insulin concentration, a given percentage change of insulin sensitivity results in a proportional change to glucose disposal and thus glycemic level, all else equal.

Understanding the variability of insulin sensitivity, over hours and days, is important for safely and effectively managing glycemic levels with exogenous insulin. Several patient- and treatment-related factors influence insulin sensitivity. Some of the influential and predictable factors (drug therapies and existing patient conditions) are taken into account when developing therapeutic algorithms for insulin treatment.

The objective of this study was to examine the evolution of insulin sensitivity level and variability over the first 4 days of intensive care unit (ICU) stay using data from the SPRINT TGC study [1]. Analyses were performed on two separate timescales, using 24-hour and 6-hour blocks of data. The impact of this insulin sensitivity evolution on glycemia in the context of TGC protocols is considered.

\section{Methods}

\section{Patients}

This study is a retrospective analysis of patient data $(\mathrm{N}=164$ patients, 12,067 hours $)$ from the SPRINT clinical practise change in the Christchurch Hospital ICU [1]. All patients admitted between August 2005 and May 2007 were included where the SPRINT TGC protocol was commenced within 12 hours of ICU admission and continued for at least 24 hours. All patients were treated per protocol, with no specific exclusions. Table 1 presents a summary of cohort details.

The Christchurch Hospital ICU is a 15-bed, closed, mixed medical-surgical unit led by intensive care specialists in a tertiary affiliated teaching hospital. Glycemic control data were collected from handwritten daily ICU charts and entered into a spreadsheet database. The Upper South Regional Ethics Committee, New Zealand, granted approval for the audit, analysis, and publication of this data.

\section{The SPRINT protocol}

The SPRINT protocol (SPecialised Relative Insulin Nutrition Tables) is a simple, lookup-table system derived
Table 1 Summary details of the study subjects

\begin{tabular}{lc}
\hline $\mathbf{N}$ & $\mathbf{1 6 4}$ \\
\hline Age (yr) & $65[56-74]$ \\
Gender (M/F) & $102 / 62$ \\
APACHE II sCore & $19[16-25]$ \\
APACHE II ROD (\%) & $32[17-52]$ \\
Operative/nonoperative & $66 / 98$ \\
Hospital mortality & $25 \%$ \\
ICU mortality & $18 \%$ \\
ICU length of stay (hr) & $142[70-308]$ \\
Diabetic history: type I/type II & $10 / 22$ \\
\hline
\end{tabular}

Data are presented as median [interquartile range] where appropriate.

from a model-based controller that modulates both insulin and nutritional inputs. The protocol titrates insulin doses and nutrition rates to estimated patient-specific insulin sensitivity for tight glycemic control in the range $4.0-6.1 \mathrm{mmol} / \mathrm{L}$ BG range $[1,13,14]$. SPRINT has been the standard of care in the Christchurch ICU since August 2005. The requirement for the patients in this study to be on the SPRINT protocol ensured that they had regular and accurate records of blood glucose levels, insulin administered, and nutrition given.

The entry criterion for the SPRINT protocol was two BG measurements $>8 \mathrm{mmol} / \mathrm{L}$ during normal patient monitoring, or at the discretion of the clinician. Once on the protocol, BG was measured 1- to 2-hourly, with a median measurement interval for this cohort of 1.5 hours. BG measurements were taken by nursing staff using the Arkray Super-Glucocard II glucometer (Arkray Inc., Japan). Blood samples tested were typically arterial, although when an arterial line was not present, capillary blood was used. Additional File 1 contains a more detailed description of SPRINT and specific, unique differences to other protocols.

\section{Model-based insulin sensitivity}

Model-based methods provide a means of determining physiological parameters that either cannot be measured directly or are impractical to measure with the required frequency. In this study, model-based insulin sensitivity (SI) was identified using an integral method [15] with a validated glucose-insulin system model developed for critical care patients $[16,17]$. The glucose-insulin system model is illustrated schematically in Figure 1 and presented in greater detail in Additional File 2.

The SI parameter represents "whole-body" insulin sensitivity. The parameter defines the glycemic response to exogenous insulin and nutrition, capturing the relative net effect of altered endogenous glucose production, peripheral and hepatic insulin mediated glucose uptake, and endogenous insulin secretion. However, this time-varying 


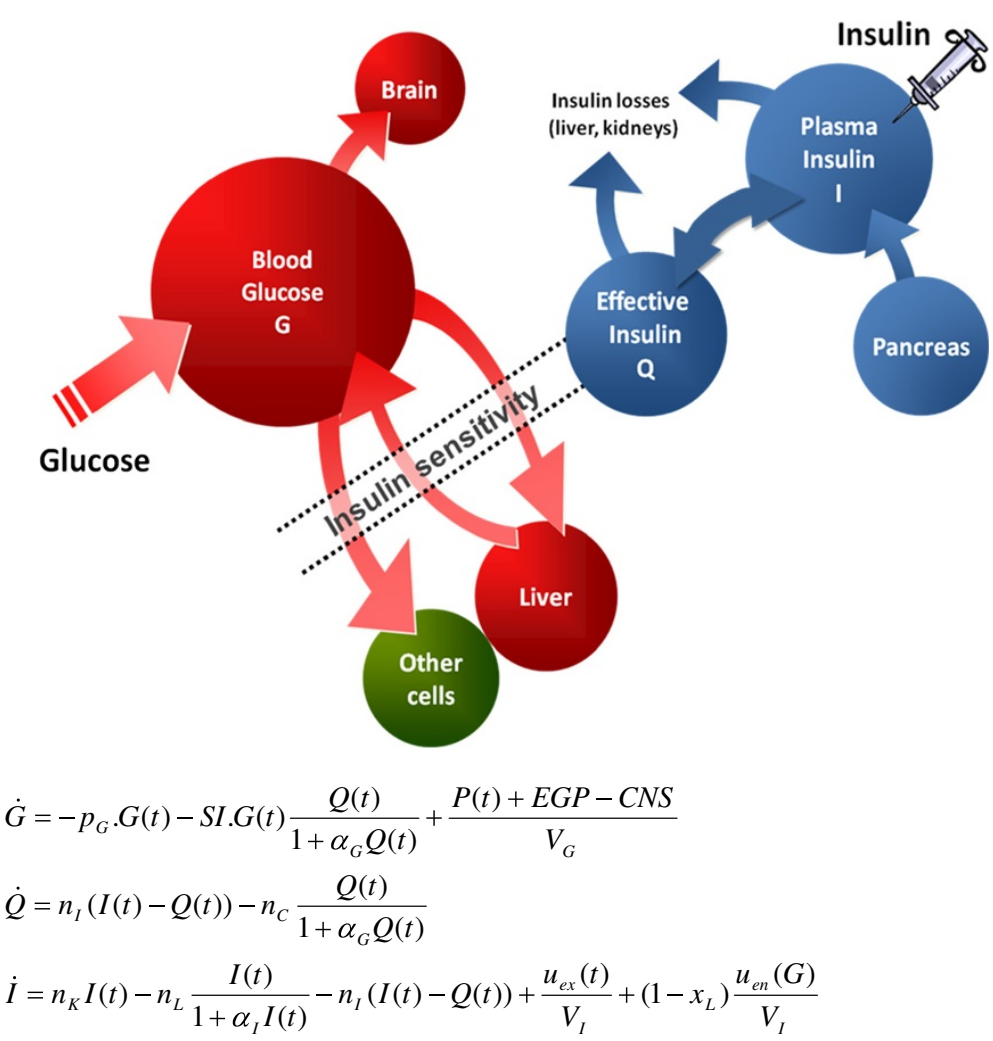

Figure 1 Schematic illustration of the glucose-insulin system model used in this analysis.

insulin sensitivity parameter has been shown to correlate very well $(r>0.9)$ with the "gold standard" euglycemic clamp [17] and has been used to guide model-based TGC in several studies [18-20].

A value of $S I$ was identified every hour [15] for each patient using clinical data and the model implemented in MATLAB (2011a, Mathworks, Natick, MA). When the BG measurement interval was greater than 1 hour, linearly interpolated values were used for identification. Variability of insulin sensitivity was calculated as the hour-to-hour percentage change in $S I(\triangle \% S I)$, defined below:

$$
\Delta \% S I_{k}=100 \times \frac{\left(S I_{k+1}-S I_{k}\right)}{S I_{k}}
$$

Use of percentage change in $S I$, rather than absolute change, normalizes the metric so that patients with very different absolute levels of SI can be compared fairly. Equally, for a fixed insulin concentration, a given percentage change in insulin sensitivity results in a proportional change to glucose disposal and thus glycemic level, all else equal.

\section{Analyses}

SI level and variability are analyzed on overall cohort and per-patient bases using two separate timescales. The evolution of SI over the first 4 days of ICU stay is analyzed in 24-hour blocks. Bagshaw [12] reported an association between hypoglycemia and variability during the first 24 hours of ICU stay and mortality. We therefore also analyzed the acute evolution of SI over the first day using 6-hour blocks.

Cohort analysis looks at the hourly values of $S I$ and variability for the entire cohort grouped together and shows trends in the overall group behavior. To quantify perpatient variability, the interquartile range (IQR: $25^{\text {th }}-75^{\text {th }}$ percentile) of $\Delta \% S I$ is examined for each patient within each timescale. This metric captures the width of the variability distribution for each patient. Per-patient $S I$ level is defined by the median value within each timescale.

The analyses are linked to time on the SPRINT protocol, rather than time in the ICU, to ensure sufficient insulin and nutrition data to accurately identify $S I$ hourly [15]. Hence, day 1 comprises the first 24 hours of SPRINT. However, because patients were included only if they commenced SPRINT within 12 hours of ICU admission, a minimum of half of the day 1 results for each patient occur during their first 24 hours in the ICU. The median delay between admission and commencement of SPRINT for this cohort was 1.9 hours and $81 \%$ of the cohort was on SPRINT within 6 hours. When a patient was taken off the SPRINT protocol, their SI profile for the last day was 
included in the analysis only if it contained 6 hours or more of data.

SI levels and variability are non-Gaussian and thus compared using cumulative distribution functions (CDFs) and nonparametric statistics. Distributed data are generally compared using the Wilcoxon rank-sum test (Mann-Whitney $U$ test), except for $S I$ variability results. $S I$ variability is compared using the KolmogorovSmirnov test, because it has more power to detect differences in the shape of distributions than the rank-sum test when median values are similar. $P<0.05$ are considered statistically significant.

\section{Results}

\section{Twenty-four hour analyses}

\section{Insulin sensitivity level}

Figure 2 presents the cumulative distribution functions (CDFs) of hourly SI for each day by cohort (left panel) and median daily SI per-patient (right panel). Table 2 presents the increase in median insulin sensitivity and associated $p$ values between successive days. Both per-patient and cohort analyses suggest that insulin sensitivity levels start low, but increase over time in the ICU. There is a particularly significant increase between days 1 and $2(p<0.001)$. On subsequent days the increase continues but to a lesser degree. Per-patient comparisons between days 2, 3, and 4 are not statistically significant.

The results of Figure 2 and Table 2 are further reflected in Table 3, which shows that daily median insulin sensitivity increases for a large proportion of the cohort between days 1 and 2 with lesser proportions on subsequent days. Table 3 is a matrix where the value in a cell represents the
Table 2 Increasing cohort and per-patient median insulin sensitivity over time (24-hr blocks)

\begin{tabular}{lcccccc}
\hline Level & \multicolumn{2}{c}{ Cohort analysis } & & \multicolumn{2}{c}{ Per-patient analysis } \\
\cline { 2 - 3 } & $\begin{array}{l}\text { \% Increase } \\
\text { at median }\end{array}$ & $\boldsymbol{p}$ value & & $\begin{array}{l}\text { \% Increase } \\
\text { at median }\end{array}$ & $\boldsymbol{p}$ value \\
\hline Days 1-2 & 34 & $<0.0001$ & & 33 & 0.0004 \\
Days 2-3 & 16 & $<0.0001$ & & 21 & 0.2559 \\
Days 3-4 & 6 & 0.0013 & & 4 & 0.6306 \\
\hline
\end{tabular}

$P$ values calculated using Wilcoxon rank-sum test.

proportion of patients for whom daily median insulin sensitivity is greater on the day of the associated column than the day of the associated row. For example, $72 \%$ of patients show an increase in median $S I$ between days 1 and 2 , and $54 \%$ when comparing days 2 and 3 .

\section{Insulin sensitivity variability}

SI variability decreases over time in the ICU, parallel to increases in absolute SI level. Figure 3 and Table 4 present the CDFs and tabulated results for cohort and per-patient analyses of the hour-to-hour percentage changes in $S I(\Delta \% S I)$. The cohort aggregate distributions of $\Delta \% S I$ by day are shown in the left panel of Figure 3. The right panel presents the CDFs for the per-patient IQRs by day.

As with insulin sensitivity level, the largest increase in $S I$ variability is between days 1 and 2 . The decrease between days 2,3 , and 4 is statistically significant for both cohort and per-patient analyses, but the change is much less than over the first day and may not be clinically significant.
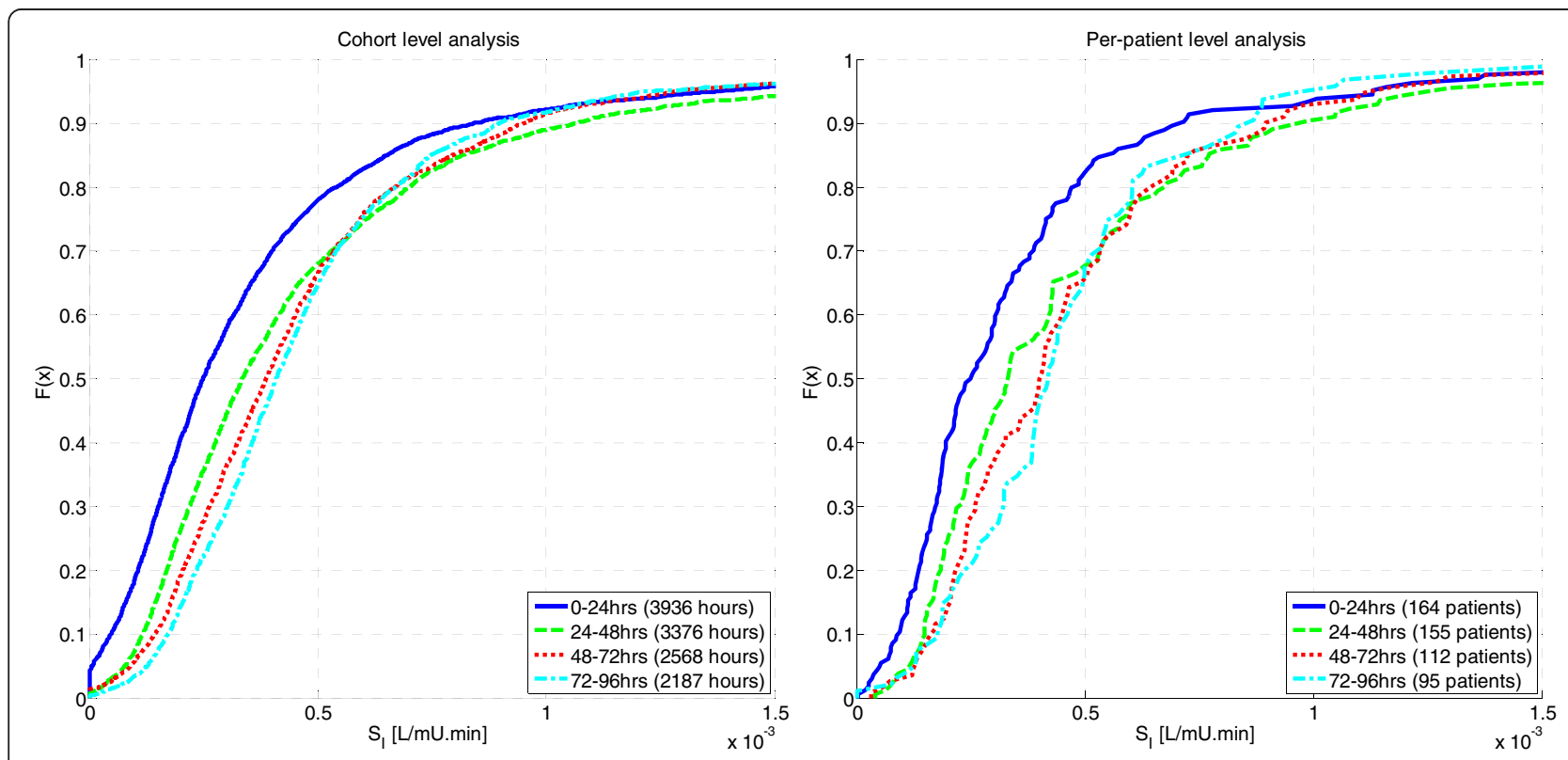

Figure 2 Insulin sensitivity level distributions by cohort (left) and per-patient median (right) using 24-hr blocks of data. 
Table 3 Proportion of patients for whom median insulin sensitivity increases between the days indicated in the rows and columns

\begin{tabular}{lccc}
\hline & Day 2 & Day 3 & Day 4 \\
\hline Day 1 & 0.72 & 0.74 & 0.71 \\
Day 2 & & 0.54 & 0.64 \\
Day 3 & & & 0.53 \\
\hline
\end{tabular}

\section{Six-hour analyses}

Insulin sensitivity level

Figure 4 presents the distributions of cohort and perpatient insulin sensitivity over the first 24 hours in 6hour blocks. Also shown for comparison is the day 2 distribution from Figure 1 (labeled 24-28 hours). It is evident that the insulin sensitivity level increases over the first day up to the level of the second day. Hence, the differences between day 1 and 2 seen in Figure 2 are a function of the low, but increasing, insulin sensitivity during the first $12-18$ hours.

Table 5 lists the differences in median insulin sensitivity levels from the distributions shown in Figure 4. The increases in SI during the first 18 hours are large and statistically significant. Subsequent increases are unlikely to be clinically significant at less than $10 \%$. Of particular interest is the comparison between 18-24 hours and day 2 , which indicates that by 18 hours, the rapid increase in $S I$ is largely complete.

Table 6 shows that during the first 18 hours, a large proportion of the patients have an increase of insulin sensitivity using the 6-hour timescale. After 18 hours,
Table 4 Reductions in the interquartile range (IQR) and median per-patient range of hour-to-hour percentage insulin sensitivity change over time

\begin{tabular}{lcccccc}
\hline $\begin{array}{l}\text { Variability } \\
\text { analysis }\end{array}$ & \multicolumn{2}{c}{ Cohort analysis } & & \multicolumn{2}{c}{ Per-patient analysis } \\
\cline { 2 - 3 } $\begin{array}{l}\text { \% Reduction } \\
\text { of IQR }\end{array}$ & p-value & & $\begin{array}{c}\text { \% Decrease } \\
\text { at median }\end{array}$ & p value \\
\hline Days 1-2 & 32 & $<0.0001$ & & 36 & $<0.0001$ \\
Days 2-3 & 20 & 0.0028 & & 18 & 0.0091 \\
Days 3-4 & 14 & 0.0269 & & 17 & 0.0369
\end{tabular}

$P$ values calculated using Kolmogorov-Smirnov test for cohort comparisons and Wilcoxon rank-sum test for per-patient comparisons.

the proportion of patients with increasing $S I$ is similar to that seen between days 2,3 , and 4 (Table 3 ) at slightly more than $50 \%$.

\section{Insulin sensitivity variability}

As with absolute $S I$ level, the majority of the decrease in $S I$ variability occurred during the first 18 hours. Figure 5 shows the CDFs of the cohort and per-patient variability metrics. Table 7 shows that only the differences between 0-6 hours and 6-12 hours are statistically significant at the $5 \%$ level. The $6-12$ vs. $12-18$-hour comparison is close to statistical significance, with $p<0.07$ for both cohort and per-patient analyses.

\section{Discussion}

Insulin sensitivity variability

Both cohort and per-patient results suggest that critically ill patients have significantly lower and more variable insulin sensitivity on day 1 than later in their ICU stay.

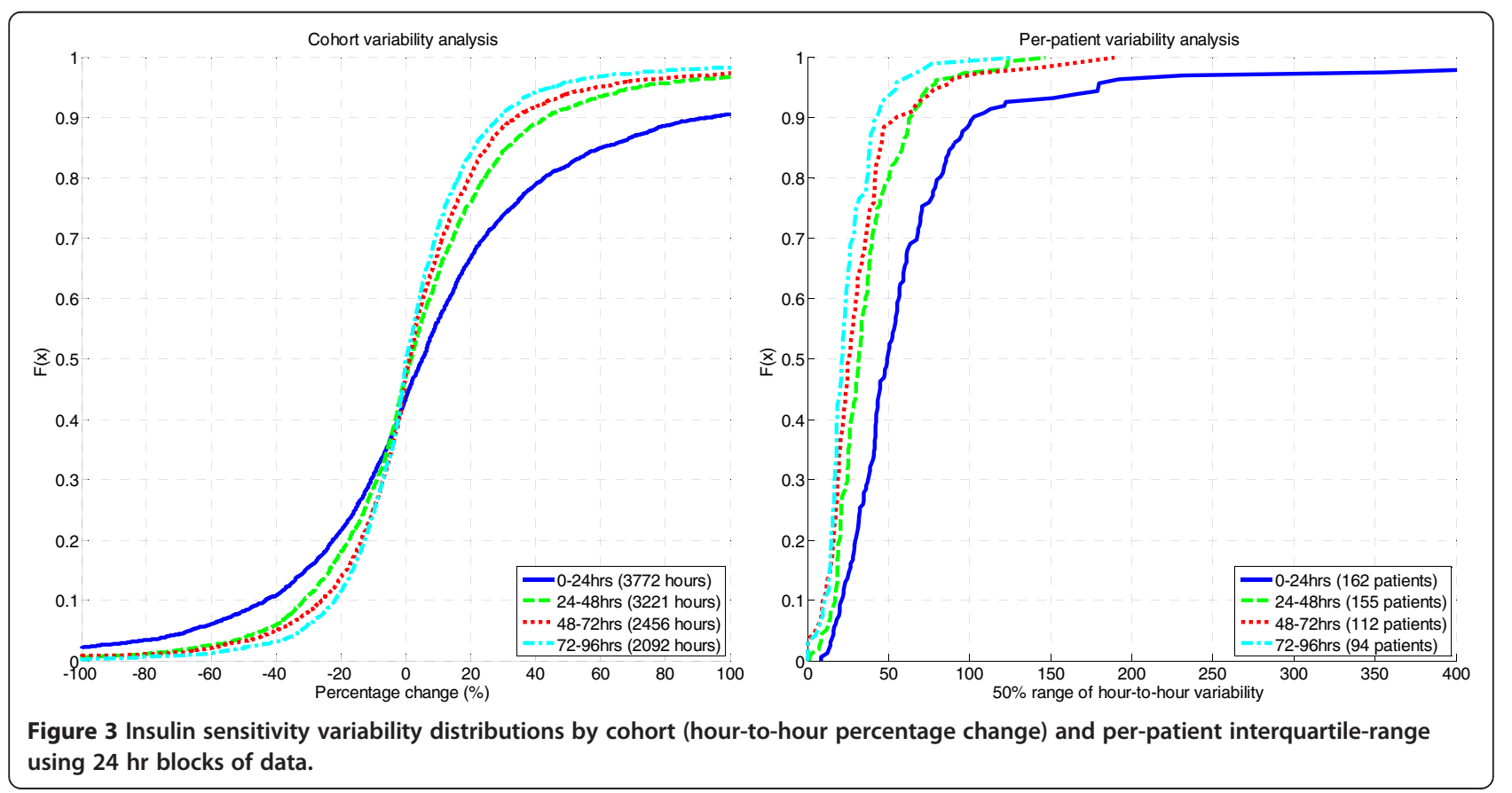



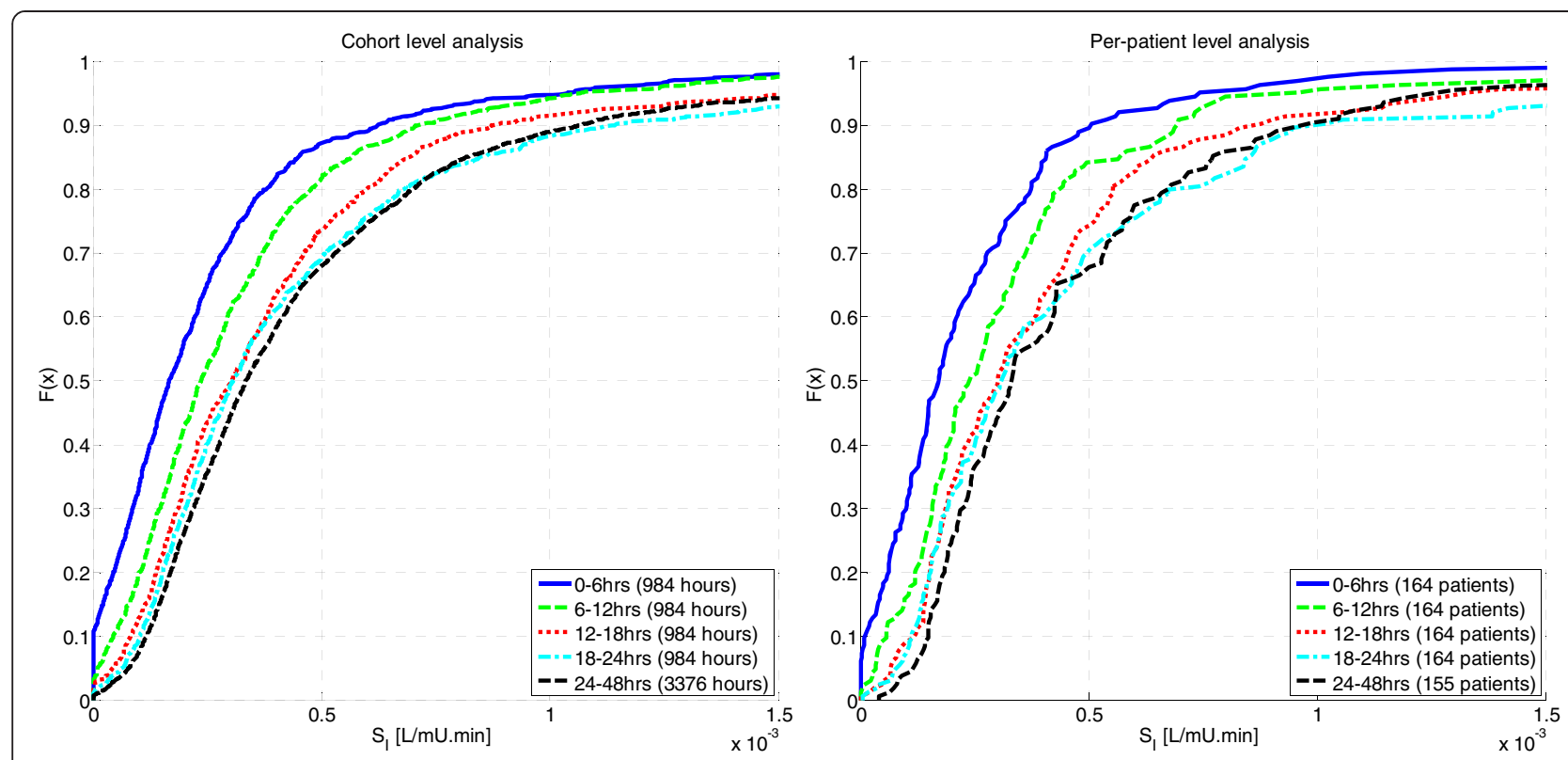

Figure 4 Insulin sensitivity level distributions by cohort (left) and per-patient median (right) using 6-hr blocks of data.

Further analysis shows that this day 1 result is primarily influenced by the first 12-18 hours of ICU stay. Over this time, rapid improvements in insulin sensitivity level and variability occur so that there is no statistically significant difference between 18-24 hours and day 2. From day 2 onwards, changes in $S I$ level and variability are not as large and of limited clinical and statistical significance.

Within the analyses, there are some differences in significance between cohort and per-patient results for comparisons after day 2 . The overall findings noted in the preceding paragraph are the only clear, consistent trends across both analyses.

The counter-regulatory hormones: cortisol, glucagon, the catecholamines, as well as growth hormone are significantly elevated almost immediately after critical-insult, but decline rapidly over the first 12-48 hours [21-24]. These hormones are known to cause increased hepatic

Table 5 Increasing cohort and per-patient median insulin sensitivity over time (6-hr blocks)

\begin{tabular}{lccccc}
\hline Level analysis & \multicolumn{2}{c}{ Cohort analysis } & & \multicolumn{2}{c}{ Per-patient analysis } \\
\cline { 2 - 3 } $\begin{array}{l}\text { \% Increase } \\
\text { at median }\end{array}$ & $\boldsymbol{p}$ value & $\begin{array}{l}\text { \% Increase } \\
\text { at median }\end{array}$ & $\boldsymbol{p}$ value \\
\hline $\begin{array}{l}\text { Block 1-2 } \\
\text { (0-6 vs. 6-12 hr) }\end{array}$ & 42 & $<0.0001$ & 40 & 0.0007 \\
$\begin{array}{l}\text { Block 2-3 } \\
\text { (6-12 vs. 12-18 hr) }\end{array}$ & 28 & $<0.0001$ & 26 & 0.0123 \\
$\begin{array}{l}\text { Block 3-4 } \\
(\mathbf{1 2 - 1 8} \text { vs. 18-24 hr) }\end{array}$ & 1 & 0.0335 & 3 & 0.4829 \\
$\begin{array}{l}\text { Block 4-5 } \\
(\mathbf{1 8 - 2 4} \text { vs. 24-48 hr) }\end{array}$ & 9 & 0.0452 & 7 & 0.3776 \\
\hline
\end{tabular}

$P$ values calculated using Wilcoxon rank-sum test. glucose production, inhibition of insulin release, and peripheral insulin resistance [22], all of which cause a decrease in the model-based SI metric used in this study. Hence, the low but rapidly increasing insulin sensitivity seen during the first $12-18$ hours of ICU stay is likely due to the acute counter-regulatory response to critical illness.

Time in this study was referenced from the commencement of SPRINT, rather than ICU admission. However, the difference between admission time and commencing SPRINT was generally very short, with a median delay for this cohort of 1.9 hours. Within 6 hours of admission, $81 \%$ of the cohort had commenced SPRINT. Hence, these results are applicable to the first few hours and days of ICU stay.

\section{The insulin sensitivity parameter}

The model-based parameter used in this study represents a whole-body insulin sensitivity capturing overall metabolic response to exogenous insulin. SI captures the relative net effect of altered hepatic glucose production, peripheral and hepatic insulin-mediated glucose uptake, and endogenous insulin secretion. All of these effects

Table 6 Proportion of patients for whom median insulin sensitivity increases between the blocks indicated in the rows and columns

\begin{tabular}{lcccc}
\hline & $\mathbf{6 - 1 2} \mathbf{~ h r}$ & $\mathbf{1 2 - 1 8} \mathbf{~ h r}$ & $\mathbf{1 8 - 2 4} \mathbf{~ h r}$ & $\mathbf{2 4 - 4 8} \mathbf{~ h r}$ \\
\hline $\mathbf{0 - 6} \mathbf{~ h r}$ & 0.74 & 0.78 & 0.77 & 0.79 \\
$\mathbf{6 - 1 2} \mathbf{~ h r}$ & & 0.76 & 0.7 & 0.72 \\
$\mathbf{1 2 - 1 8} \mathbf{~ h r}$ & & & 0.55 & 0.64 \\
$\mathbf{1 8 - 2 4} \mathbf{~ h r}$ & & & & 0.58 \\
\hline
\end{tabular}



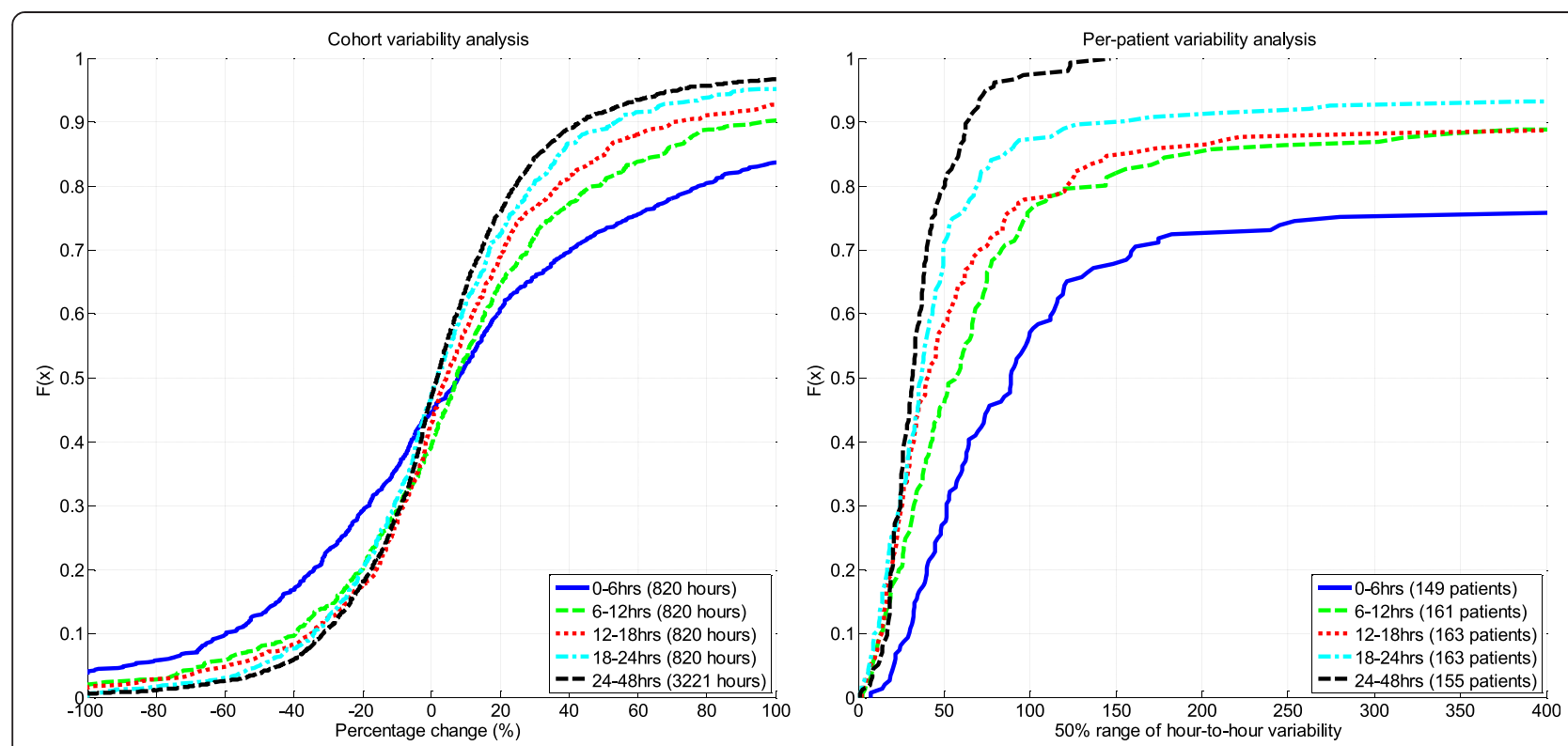

Figure 5 Insulin sensitivity variability distributions by cohort (hour-to-hour percentage change) and per-patient interquartile-range using 6-hr blocks of data.

are altered significantly in critical illness due to the stress response [25-27]. Hence, the metabolic balance that this parameter represents is an important consideration in TGC, because it determines a body's glycemic response to exogenous insulin and nutrition.

As an identified parameter, SI contains unmodeled physiological effects and measurement device noise. However, Lotz et al. [17] indicated that this form of insulin sensitivity correlated very well $(r>0.9)$ with the "gold standard" euglycemic clamp and its change in a lifestyle intervention study on 73 normoglycemic healthy and obese subjects (146 clamp procedures before/after intervention). In the critical care setting, a similar version of the model and $S I$ parameter has been cross-validated

Table 7 Reductions of the interquartile range (IQR) and median per-patient range of hour-to-hour percentage insulin sensitivity change over time

\begin{tabular}{|c|c|c|c|c|}
\hline \multirow{2}{*}{$\begin{array}{l}\text { Variability } \\
\text { analysis }\end{array}$} & \multicolumn{2}{|c|}{ Cohort analysis } & \multicolumn{2}{|c|}{ Per-patient analysis } \\
\hline & $\begin{array}{l}\% \text { Reduction } \\
\text { of IQR }\end{array}$ & $p$ value & $\begin{array}{l}\% \text { Decrease } \\
\text { at median }\end{array}$ & $p$ value \\
\hline $\begin{array}{l}\text { Block 1-2 } \\
\text { (0-6 vs. 6-12 hr) }\end{array}$ & 40 & 0.0017 & 36 & $<0.0001$ \\
\hline $\begin{array}{l}\text { Block 2-3 } \\
\text { (6-12 vs. 12-18 hr) }\end{array}$ & 24 & 0.0628 & 28 & 0.0673 \\
\hline $\begin{array}{l}\text { Block 3-4 } \\
\text { (12-18 vs. } 18-24 \text { hr) }\end{array}$ & 0 & 0.0931 & 9 & 0.1032 \\
\hline $\begin{array}{l}\text { Block 4-5 } \\
\text { (18-24 vs. } 24-48 \text { hr) }\end{array}$ & 18 & 0.1682 & 14 & 0.1075 \\
\hline
\end{tabular}

$P$ values calculated using Kolmogorov-Smirnov test for cohort comparisons and Wilcoxon rank-sum test for per-patient comparisons. against independent, matched patient data from a single center of the Glucontrol randomized, clinical trial [28].

The analytic inaccuracy of bedside glucometers or any other sensor used to gather BG measurements influence individual values of SI. However, this study examines distributions of SI consisting of thousands of values identified from a wide range of BG values, thus both the random and bias components of error cancel out within each distribution. This effect was confirmed by Monte Carlo analysis (results not shown) using an error model for the glucometer derived from data supplied by the manufacturer [29].

\section{Implications for tight glycemic control}

With low and variable insulin sensitivity, glycemic levels may appear unresponsive and/or difficult to control effectively with exogenous insulin. This situation may provoke larger insulin doses from many protocols that have no explicit upper limits on insulin dose [6,30-32]. High levels of circulating insulin coupled with the observed variability in insulin sensitivity result in increased glycemic variability and an increased risk of hypoglycemia during the first 24 hours of ICU stay.

Not only does glycemic variability pose a risk through hypoglycemia, it also is detrimental in its own right. Several studies $[9-11,33]$ have shown that glycemic variability is independently associated with mortality in critically ill patients. More specifically, Bagshaw [12] showed that hypoglycemia and variability within the first 24 hours of ICU stay are each associated with increased mortality. In vitro, high glycemic variability was shown to increase 
oxidative stress [34] and apoptosis [35], thereby suggesting a rationale to explain the clinical association with poor outcome.

Evidence from other studies [10,12] indicates an association between hypoglycemia, glycemic variability, and mortality. However, the question remains: Is low and variable glycemia the cause of increased morbidity and mortality? Or is it just a symptom in very ill patients? Until this question can be answered conclusively, it is perhaps best to formulate TGC protocols not to exacerbate the situation, which requires the ability to differentiate more and less metabolically variable patients.

Another significant finding in this study is the range of variability seen across patients, as well as over time (Figures 3 and 5). Less variable patients, if identified, may be treated more aggressively with insulin without compromising glycemic variability. Hence, model-based methods have been mooted as a means of better managing this inter- and intra-patient variability $[30,36]$.

\section{Limitations}

Only patients on the SPRINT TGC protocol were considered for this analysis as they had sufficient data density to identify SI hourly. Patients were put on the SPRINT protocol because they were hyperglycemic and thus were likely to be biased towards lower insulin sensitivity compared with other ICU patients. However, in the context of investigating the implications of $S I$ variability on TGC, this cohort is appropriate.

Another limitation is the use of a model-based insulin sensitivity parameter, as it is not measured directly and may be influenced by modelling errors or un-modelled effects. As an identified parameter, SI contains unmodeled physiological effects and measurement device noise. However, as noted previously, this form of SI has been shown to correlate very well with the "gold standard" euglycemic clamp [17,37] and has been shown to be an independent marker of metabolic condition [28]. Finally, this method of analysis is robust to BG sensor error.

A further limitation is the relatively small cohort size available for analysis. The demands of manually transcribing written clinical data into electronic form and the specific inclusion criteria have restricted the number of patients for whom complete glycemic control data are currently available for analysis. The size of this cohort has precluded subgroup analyses, such as diabetic and cardiovascular surgery patients, because these subgroups only contain 20-40 patients. With relatively few patients, the subgroup analyses fail to demonstrate statistical significance, despite effect sizes and trends very similar to that seen in this overall analysis. Thus, these comparisons will be completed in the future, when more patient data become available.
The findings of this study should be equally valid in other ICUs where attention to TGC and blood glucose measurement frequency may be a lower priority. Although the data density might not be present to allow such units to explicitly identify SI hourly, these results indicate that patients will still have lower and more variable insulin sensitivity on day 1 than later in their ICU stay. Thus, suggestions of higher glycemic targets, conservative insulin dosing, and modulation of carbohydrate nutrition are especially pertinent.

Without the ability to identify patient-specific metabolic states, a protocol should be less aggressive over the first few days, and particularly the first 24 hours, to minimize variability. It may be important for protocols to consider higher glycemic targets on the first days of ICU stay (compared with later days) to ensure safety. Perhaps a glycemic target similar to the current guidelines of 7.8-11 $\mathrm{mmol} / \mathrm{L}$ [38-40] is most appropriate for the first 24 hours with the target range, reducing over days 2 and 3 to more normoglycemic levels as $S I$ level and variability improve.

Greater blood glucose measurement frequency and conservative insulin dosing can mitigate the impact of $S I$ variability on risk [41] and also should be considered for the first few days of stay. Modulation of carbohydrate nutrition, within limits [42], can reduce the need for exogenous insulin to better manage glycemia [43].

\section{Conclusions}

The results of this study indicate that critically ill patients have significantly lower and more variable insulin sensitivity on day 1 than later in their ICU stay, particularly during the first $12-18$ hours. This effect is likely due to the acute counter-regulatory response to critical illness. Greater variability with lower SI early in a patient's stay greatly increases the insulin required, potential glucose flux due to variation in $S I$, and thus the risk of greater glycemic variability and hypoglycemia. Both glycemic variability and hypoglycemia have been associated with poor outcomes in the ICU.

Clinically, these results suggest that TGC patients require greater care over the first few days of ICU stay to minimize safely the outcome glycemic variability. It may be important for protocols to consider higher glycemic targets on the first days of ICU stay to ensure safety. Equally, greater measurement frequency, conservative insulin dosing, and modulation of carbohydrate nutrition can mitigate the impact of variability on risk and should be considered for the first few days of stay.

\section{Additional files}

Additional file 1: Detailed description of the SPRINT protocol, listing unique features and differences to other TGC protocols. Additional file 2: Detailed description of the glucose-insulin system model and the SI parameter [19,43-74]. 


\section{Abbreviations}

ICU: Intensive care unit; SPRINT: Specialized relative insulin and nutrition titration; TGC: Tight glycemic control; SI: Insulin sensitivity metric (model-based); $\Delta \%$ Sl: Hour-to-hour percentage changes in insulin sensitivity; CDF: Cumulative distribution function; IQR: Interquartile range; APACHE: Acute physiology and chronic health evaluation; KS: Kolmogorov-Smirnov (test).

\section{Competing interests}

The authors declare that they have no competing interests.

\section{Acknowledgments}

Financial support provided by:

Christopher PRETTY: NZ Tertiary Education Commission Top Achiever Doctoral Scholarship

Aaron LE COMPTE: New Zealand Tertiary Education Commission and NZ Foundation for Research Science and Technology Post-Doctoral Fellowship Grant

Sophie PENNING: FNRS (Fonds Nationale de la Recherche Scientifique) Research Fellow

\section{Author details}

'Department of Mechanical Eng, Centre for Bio-Engineering, University of Canterbury, Private Bag 4800, Christchurch 8054, New Zealand. ${ }^{2}$ Department of Intensive Care, Christchurch Hospital, Christchurch 8054, New Zealand. ${ }^{3}$ Department of Intensive Care, CUB Hospital Erasme, Free University of Brussels, Route de Lennik 808, Brussels 1070, Belgium. ${ }^{4}$ Cardiovascular Research University of Liege, Liege, Belgium.

\section{Authors' contributions}

JGC, GS, and ALC conceived and developed the SPRINT protocol. GS implemented the protocol with staff at Christchurch Hospital. CGP, ALC, JGC, $\mathrm{GS}, \mathrm{TD}, \mathrm{J}-\mathrm{CP}$, and SP assisted with the data analysis, idea generation, some (or all) data collection, and/or the analysis and interpretation of the data and/or statistical analysis. CGP, JGC, and ALC drafted the manuscript primarily, although all of the authors made contributions. All authors read and approved the final manuscript.

Received: 9 December 2011 Accepted: 15 June 2012 Published: 15 June 2012

\section{References}

1. Chase JG, Shaw G, Le Compte A, Lonergan T, Willacy M, Wong X-W, Lin J, Lotz T, Lee D, Hann C: Implementation and evaluation of the SPRINT protocol for tight glycaemic control in critically ill patients: a clinical practice change. Crit Care 2008, 12(2):R49.

2. Van den Berghe G, Wilmer A, Hermans G, Meersseman W, Wouters PJ, Milants I, Van Wijngaerden E, Bobbaers H, Bouillon R: Intensive insulin therapy in the medical ICU. N Engl J Med 2006, 354(5):449-461.

3. Van den Berghe G, Wouters P, Weekers F, Verwaest C, Bruyninckx F, Schetz $M$, Vlasselaers D, Ferdinande P, Lauwers P, Bouillon R: Intensive insulin therapy in the critically ill patients. N Engl J Med 2001, 345(19):1359-1367.

4. Krinsley JS: Decreased mortality of critically ill patients with the use of an intensive glycemic management protocol. Crit Care Med 2003, 31:A19.

5. Finfer S, Chittock DR, Su SY, Blair D, Foster D, Dhingra V, Bellomo R, Cook D, Dodek P, Henderson WR, et al: Intensive versus conventional glucose control in critically ill patients. N Engl J Med 2009, 360(13):1283-1297.

6. Preiser JC, Devos P, Ruiz-Santana S, Melot C, Annane D, Groeneveld J, lapichino $G$, Leverve $X$, Nitenberg $G$, Singer $P$, et al: A prospective randomised multi-centre controlled trial on tight glucose control by intensive insulin therapy in adult intensive care units: the Glucontrol study. Intensive Care Med 2009, 35(10):1738-1748.

7. Brunkhorst FM, Engel C, Bloos F, Meier-Hellmann A, Ragaller M, Weiler N, Moerer $\mathrm{O}$, Gruendling $\mathrm{M}$, Oppert $\mathrm{M}$, Grond $\mathrm{S}$, et al: Intensive insulin therapy and pentastarch resuscitation in severe sepsis. N Engl J Med 2008, 358(2):125-139.

8. Chase JG, Le Compte AJ, Suhaimi F, Shaw GM, Lynn A, Lin J, Pretty CG, Razak N, Parente JD, Hann CE, et al: Tight glycemic control in critical care - The leading role of insulin sensitivity and patient variability: A review and model-based analysis. Comput Methods Programs Biomed 2011, 102(2):156-171.
9. Egi M, Bellomo R, Stachowski E, French CJ, Hart G: Variability of blood glucose concentration and short-term mortality in critically ill patients. Anesthesiology 2006, 105(2):244-252.

10. Egi M, Bellomo R, Stachowski E, French CJ, Hart GK, Taori G, Hegarty C, Bailey M: Hypoglycemia and outcome in critically ill patients. Mayo Clin Proc 2010, 85(3):217-224.

11. Krinsley JS: Glycemic variability: a strong independent predictor of mortality in critically ill patients. Crit Care Med 2008, 36(11):3008-3013.

12. Bagshaw SM, Bellomo R, Jacka MJ, Egi M, Hart GK, George C: The impact of early hypoglycemia and blood glucose variability on outcome in critical illness. Crit Care 2009, 13(3):R91.

13. Chase JG, Shaw GM, Lotz T, LeCompte A, Wong J, Lin J, Lonergan T, Willacy M, Hann CE: Model-based insulin and nutrition administration for tight glycaemic control in critical care. Curr Drug Deliv 2007, 4(4):283-296.

14. Lonergan T, Le Compte A, Willacy M, Chase JG, Shaw GM, Hann CE, Lotz T, Lin J, Wong XW: A pilot study of the SPRINT protocol for tight glycemic control in critically III patients. Diabetes Technol Ther 2006, 8(4):449-462.

15. Hann CE, Chase JG, Lin J, Lotz T, Doran CV, Shaw GM: Integral-based parameter identification for long-term dynamic verification of a glucoseinsulin system model. Comput Methods Programs Biomed 2005, 77(3):259-270.

16. Lin J, Razak NN, Pretty CG, Le Compte A, Docherty P, Parente JD, Shaw GM, Hann CE, Geoffrey Chase J: A physiological Intensive Control InsulinNutrition-Glucose (ICING) model validated in critically ill patients. Comput Methods Programs Biomed 2011, 102(2):192-205.

17. Lotz TF, Chase JG, McAuley KA, Shaw GM, Wong XW, Lin J, Lecompte A, Hann CE, Mann Jl: Monte Carlo analysis of a new model-based method for insulin sensitivity testing. Comput Methods Programs Biomed 2008, 89 (3):215-225.

18. Evans A, Shaw GM, Le Compte A, Tan CS, Ward L, Steel J, Pretty CG, Pfeifer $L$, Penning S, Suhaimi F, et al: Pilot proof of concept clinical trials of Stochastic Targeted (STAR) glycemic control. Ann Intensive Care 2011, 1:38.

19. Le Compte A, Chase J, Lynn A, Hann C, Shaw G, Wong X, Lin J: Blood Glucose Controller for Neonatal Intensive Care: Virtual trials development and 1st clinical trials. J Diabetes Sci Technol 2009, 3(5):1066-1081.

20. Shaw GM, Chase JG, Wong J, Lin J, Lotz T, Le Compte AJ, Lonergan TR, Willacy MB, Hann CE: Rethinking glycaemic control in critical illness from concept to clinical practice change. Crit Care Resusc 2006, 8(2):90-99.

21. Chernow B, Alexander HR, Smallridge RC, Thompson WR, Cook D, Beardsley $D$, Fink MP, Lake CR, Fletcher JR: Hormonal responses to graded surgical stress. Arch Intern Med 1987, 147(7):1273-1278

22. Weissman C: The metabolic response to stress: an overview and update. Anesthesiology 1990, 73(2):308-327.

23. Frayn KN: Hormonal control of metabolism in trauma and sepsis. Clin Endocrinol (Oxf) 1986, 24(5):577-599.

24. Jaattela A, Alho A, Avikainen V, Karaharju E, Kataja J, Lahdensuu M, Lepisto $P$, Rokkanen P, Tervo T: Plasma catecholamines in severely injured patients: a prospective study on 45 patients with multiple injuries. $\mathrm{Br} J$ Surg 1975, 62(3):177-181.

25. Black PR, Brooks DC, Bessey PQ, Wolfe RR, Wilmore DW: Mechanisms of insulin resistance following injury. Ann Surg 1982, 196(4):420-435.

26. Deibert DC, Defronzo RA: Epinephrine-induced insulin resistance in man. J Clin Invest 1980, 65(3):717-721.

27. Thorell A, Rooyackers O, Myrenfors P, Soop M, Nygren J, Ljungqvist OH: Intensive insulin treatment in critically ill trauma patients normalizes glucose by reducing endogenous glucose production. I Clin Endocrinol Metab 2004, 89(11):5382-5386.

28. Chase JG, Suhaimi F, Penning S, Preiser JC, Le Compte AJ, Lin J, Pretty CG, Shaw GM, Moorhead KT, Desaive T: Validation of a model-based virtual trials method for tight glycemic control in intensive care. Biomed Eng Online 2010, 9:84.

29. Arkray: Glucocard ${ }^{\mathrm{TM}}$ Test Strip 2 Data Sheet. apan: Arkray Inc; 2007.

30. Chase J, Shaw GM, Wong XW, Lotz T, Lin J, Hann CE: Model-based glycaemic control in critical care: a review of the state of the possible. Biomed Signal Proc Control 2006, 1(1):3-21.

31. Davidson PC, Steed RD, Bode BW: Glucommander: a computer-directed intravenous insulin system shown to be safe, simple, and effective in 120,618 h of operation. Diabetes Care 2005, 28(10):2418-2423.

32. Goldberg PA, Siegel MD, Sherwin RS, Halickman II, Lee M, Bailey VA, Lee SL, Dziura JD, Inzucchi SE: Implementation of a safe and effective insulin infusion protocol in a medical intensive care unit. Diabetes Care 2004, 27 (2):461-467. 
33. Hermanides J, Vriesendorp TM, Bosman RJ, Zandstra DF, Hoekstra JB, Devries $\mathrm{JH}$ : Glucose variability is associated with intensive care unit mortality. Crit Care Med 2010, 38(3):838-842

34. Piconi L, Quagliaro L, Assaloni R, Da Ros R, Maier A, Zuodar G, Ceriello A Constant and intermittent high glucose enhances endothelial cell apoptosis through mitochondrial superoxide overproduction. Diabetes Metab Res Rev 2006, 22(3):198-203.

35. Risso A, Mercuri F, Quagliaro L, Damante G, Ceriello A: Intermittent high glucose enhances apoptosis in human umbilical vein endothelial cells in culture. Am J Physiol Endocrinol Metab 2001, 281(5):E924-E930.

36. Chase JG, Compte AJL, Preiser J-C, Shaw GM, Penning S, Desaive T: Physiological modeling, tight glycemic control and the ICU clinician: what are models and how can they affect practice? Ann Intensive Care 2011, 1(1):11.

37. McAuley KA, Berkeley JE, Docherty PD, Lotz TF, Te Morenga LA, Shaw GM, Williams SM, Chase JG, Mann Jl: The dynamic insulin sensitivity and secretion test-a novel measure of insulin sensitivity. Metabolism 2011, 60 (12):1748-1756.

38. Moghissi ES, Korytkowski MT, DiNardo M, Einhorn D, Hellman R, Hirsch IB, Inzucchi SE, Ismail-Beigi F, Kirkman MS, Umpierrez GE: American Association of Clinical Endocrinologists and American Diabetes Association consensus statement on inpatient glycemic control. Diabetes Care 2009, 32(6):1119-1131.

39. Qaseem A, Humphrey LL, Chou R, Snow V, Shekelle P: Use of intensive insulin therapy for the management of glycemic control in hospitalized patients: a clinical practice guideline from the American College of Physicians. Ann Intern Med 2011, 154(4):260-267.

40. Ichai C, Preiser JC: International recommendations for glucose control in adult non diabetic critically ill patients. Crit Care 2010, 14(5):R166.

41. Lonergan T, LeCompte A, Willacy M, Chase JG, Shaw GM, Wong XW, Lotz T, Lin J, Hann CE: A simple insulin-nutrition protocol for tight glycemic control in critical illness: development and protocol comparison. Diabetes Technol Ther 2006, 8(2):191-206.

42. Krishnan JA, Parce PB, Martinez A, Diette GB, Brower RG: Caloric intake in medical ICU patients: consistency of care with guidelines and relationship to clinical outcomes. Chest 2003, 124(1):297-305.

43. Suhaimi F, Le Compte A, Preiser JC, Shaw GM, Massion P, Radermecker R, Pretty CG, Lin J, Desaive T, Chase JG: What makes tight glycemic control tight? The impact of variability and nutrition in two clinical studies. J Diabetes Sci Technol 2010, 4(2):284-298.

44. Natali A, Gastaldelli A, Camastra S, Sironi AM, Toschi E, Masoni A, Ferrannini E, Mari A: Dose-response characteristics of insulin action on glucose metabolism: a non-steady-state approach. Am J Physiol Endocrinol Metab 2000, 278(5):E794-E801.

45. Prigeon RL, Roder ME, Porte D Jr, Kahn SE: The effect of insulin dose on the measurement of insulin sensitivity by the minimal model technique. Evidence for saturable insulin transport in humans. J Clin Invest 1996, 97(2):501-507.

46. Chase JG, Shaw GM, Lin J, Doran CV, Hann C, Lotz T, Wake GC, Broughton B: Targeted glycemic reduction in critical care using closed-loop control. Diabetes Technol Ther 2005, 7(2):274-282.

47. Chase JG, Shaw GM, Lin J, Doran CV, Bloomfield M, Wake GC, Broughton B, Hann C, Lotz T: Impact of insulin-stimulated glucose removal saturation on dynamic modelling and control of hyperglycaemia. Int J Intellig Syst Technol Appl (IJISTA) 2004, 1(1/2):79-94.

48. Rubinson L, Diette GB, Song $X$, Brower RG, Krishnan JA: Low caloric intake is associated with nosocomial bloodstream infections in patients in the medical intensive care unit. Crit Care Med 2004, 32(2):350-357.

49. Cerra FB, Benitez MR, Blackburn GL, Irwin RS, Jeejeebhoy K, Katz DP, Pingleton SK, Pomposelli J, Rombeau JL, Shronts E, et al: Applied nutrition in ICU patients. A consensus statement of the American College of Chest Physicians. Chest 1997, 111(3):769-778.

50. Braithwaite SS, Edkins R, Macgregor KL, Sredzienski ES, Houston M, Zarzaur B, Rich PB, Benedetto B, Rutherford EJ: Performance of a dose-defining insulin infusion protocol among trauma service intensive care unit admissions. Diabetes Technol Ther 2006, 8(4):476-488.

51. Preiser JC: Year in review 2008: Critical Care-metabolism. Crit Care 2009, 13(5):228

52. Mesotten D, Van den Berghe $\mathrm{G}$ : Clinical benefits of tight glycaemic control: focus on the intensive care unit. Best Pract Res Clin Anaesthesiol 2009, 23(4):421-429.

53. Griesdale DE, de Souza RJ, van Dam RM, Heyland DK, Cook DJ, Malhotra A, Dhaliwal R, Henderson WR, Chittock DR, Finfer S, et al: Intensive insulin therapy and mortality among critically ill patients: a meta-analysis including NICE-SUGAR study data. CMAJ 2009, 180(8):821-827.

54. Lin J, Lee D, Chase JG, Shaw GM, Le Compte A, Lotz T, Wong J, Lonergan T, Hann CE: Stochastic modelling of insulin sensitivity and adaptive glycemic control for critical care. Compt Methods Programs Biomed 2008, 89(2):141-152.

55. Chase JG, Shaw GM, Lin J, Doran CV, Hann C, Robertson MB, Browne PM, Lotz T, Wake GC, Broughton B: Adaptive bolus-based targeted glucose regulation of hyperglycaemia in critical care. Med Eng Phys 2005, 27(1):1-11.

56. Wong XW, Singh-Levett I, Hollingsworth LJ, Shaw GM, Hann CE, Lotz T, Lin J, Wong OS, Chase JG: A novel, model-based insulin and nutrition delivery controller for glycemic regulation in critically ill patients. Diabetes Technol Ther 2006, 8(2):174-190.

57. Wong XW, Chase JG, Shaw GM, Hann CE, Lotz T, Lin J, Singh-Levett I, Hollingsworth LJ, Wong OS, Andreassen S: Model predictive glycaemic regulation in critical illness using insulin and nutrition input: a pilot study. Med Eng Phys 2006, 28(7):665-681.

58. Chase JG, Wong X-W, Singh-Levett I, Hollingsworth $\sqcup$, Hann CE, Shaw GM, Lotz T, Lin J: Simulation and initial proof-of-concept validation of a glycaemic regulation algorithm in critical care. Control Eng Pract 2008, 16(3):271-285.

59. Hann C, Chase J, Ypma M, Elfring J, Nor N, Lawrence P, Shaw G: The Impact of Parameter Identification Methods on Drug Therapy Control in an Intensive Care Unit. Open Med Inform J 2008, 2:92-104.

60. Cobelli C, Carson ER, Finkelstein L, Leaning MS: Validation of simple and complex models in physiology and medicine. Am J Physiol 1984, 246(2 Pt 2): R259-R266.

61. Cobelli C, Pacini G, Toffolo G, Sacca L: Estimation of insulin sensitivity and glucose clearance from minimal model: new insights from labeled IVGTT. Am J Physiol 1986, 250(5 Pt 1):E591-E598.

62. Carson ER, Cobelli C: Modelling methodology for physiology and medicine. San Diego: Academic; 2001

63. Cobelli C, Caumo A, Omenetto M: Minimal model SG overestimation and SI underestimation: improved accuracy by a Bayesian two-compartment model. Am J Physiol 1999, 277(3 Pt 1):E481-E488.

64. Hovorka R, Chassin LJ, Ellmerer M, Plank J, Wilinska ME: A simulation model of glucose regulation in the critically ill. Physiol Meas 2008, 29(8):959-978.

65. Pillonetto G, Sparacino G, Cobelli C: Numerical non-identifiability regions of the minimal model of glucose kinetics: superiority of Bayesian estimation. Math Biosci 2003, 184(1):53-67

66. Le Compte AJ, Lee DS, Chase JG, Lin J, Lynn A, Shaw GM: Blood glucose prediction using stochastic modeling in neonatal intensive care. IEEE Trans Biomed Eng 2010, 57(3):509-518.

67. Lin J, Lee D, Chase J, Hann C, Lotz T, Wong X: Stochastic Modelling of Insulin Sensitivity Variability in Critical Care. Biomed Signal Proc Control 2006, 1:229-242.

68. Lin J, Lee D, Chase JG, Shaw GM, Le Compte A, Lotz T, Wong J, Lonergan T, Hann CE: Stochastic modelling of insulin sensitivity and adaptive glycemic control for critical care. Comput Methods Programs Biomed 2008, 89(2):141-152.

69. Lotz TF, Chase JG, McAuley KA, Lee DS, Lin J, Hann CE, Mann Jl: Transient and steady-state euglycemic clamp validation of a model for glycemic control and insulin sensitivity testing. Diabetes Technol Ther 2006, 8(3):338-346.

70. Lotz T: High Resolution Clinical Model-Based Assessment of Insulin Sensitivity. Christchurch: University of Canterbury; 2007.

71. Lin J, Razak NN, Pretty CG, Le Compte A, Docherty P, Parente JD, Shaw GM, Hann CE: Geoffrey Chase J: A physiological Intensive Control InsulinNutrition-Glucose (ICING) model validated in critically ill patients. Comput Methods Programs Biomed 2011, 102(2):192-205.

72. McAuley KA, Williams SM, Mann Jl, Goulding A, Chisholm A, Wilson N, Story G, McLay RT, Harper MJ, Jones IE: Intensive lifestyle changes are necessary to improve insulin sensitivity: a randomized controlled trial. Diabetes Care 2002, 25(3):445-452

73. Le Compte A: Modelling the Glucose-Insulin Regulatory System for Glycaemic Control in Neonatal Intensive Care. PhD thesis. Christchurch, New Zealand: University of Canterbury; 2009.

74. Lin J: Robust Modelling and Control of the Glucose-Insulin Regulatory System for Tight Glycemic Control of Critical Care Patients. Christchurch: University of Canterbury; 2007.

doi:10.1186/2110-5820-2-17

Cite this article as: Pretty et al:: Variability of insulin sensitivity during the first 4 days of critical illness: implications for tight glycemic control. Annals of Intensive Care 2012 2:17. 